\title{
Grazing and iron limitation in the control of phytoplankton stock and nutrient concentration: a chemostat analogue of the Pacific equatorial upwelling zone
}

\author{
B. W. Frost, N. C. Franzen \\ School of Oceanography, WB-10, University of Washington, Seattle, Washington 98195, USA
}

\begin{abstract}
Grazing control and iron limitation have been portrayed as mutually exclusive alternative explanations of the high nutrient/low phytoplankton stock condition in the nutrient-rich areas of the open sea. To contrast clearly the underlying assumptions and specific consequences of the 2 mechanisms, a simple mathematical model of a chemostat containing a pelagic food chain with 1 to 4 trophic levels is used as an analogue of the equatorial upwelling zone in the eastern Pacific. It shows that grazing control is essential to reproduce 3 conditions observed in the equatorial upwelling zone: low phytoplankton stocks, high concentrations of macronutrients, and phytoplankton specific growth rates that greatly exceed advective throughput rate in the mixed layer at the equator. Nevertheless, simultaneous grazing control and limitation by a trace nutrient such as iron could feasibly account for observed phytoplankton specific growth rates that are less than the maximum rate possible under optimal growth conditions. In addition, release of an inefficiently grazed component of the phytoplankton assemblage from iron limitation seems to explain why escape from grazing control occurs under both experimental and natural iron enrichments.
\end{abstract}

\section{INTRODUCTION}

Surface waters of several large open ocean areas, viz., the subarctic Pacific, the Pacific equatorial upwelling zone, and the ice-free Southern Ocean, have low concentrations of phytoplankton year-round despite high concentrations of macronutrients (i.e. nitrate and phosphate). Consider the equatorial upwelling zone west of the Galapagos Islands to about $150^{\circ} \mathrm{W}$ in the Pacific Ocean. Normally (that is, in non-El Niño years) concentration of nitrate is $\geq 5 \mathrm{mmol} \mathrm{m}^{-3}$ in the mixed layer, being supplied by upwelling, but the phytoplankton stock in the mixed layer is only about 0.2 to $0.4 \mathrm{mg}$ chl a m${ }^{-3}$ (Chavez et al. 1990, Peña et al. 1990, Cullen et al. 1992). Since the phytoplankton specific growth rate is also high, maintenance of low phytoplankton stocks has been attributed to grazing (Peña et al. 1990, 1991, Cullen et al. 1992). Yet an alternative proposal (Martin et al. 1989, 1991) that iron limitation of phytoplankton growth is responsible for low phytoplankton stocks and high nutrients indicates that the specific mechanisms need to be reexamined.

In light of recent intense interest in the control of phytoplankton standing stock and production in the nutrientrich areas of the open sea (Chisholm \& Morel 1991), the contribution by Thingstad \& Sakshaug (1990) was particularly timely. They pointed out that control or regulation of phytoplankton stock is a property of the entire pelagic ecosystem, not solely a consequence of a single process such as nutrient limitation or grazing. The purpose of this paper is to elaborate Thingstad \& Sakshaug's (1990) argument, also using a model, to contrast the underlying assumptions and specific consequences of the 2 hypothesized control mechanisms, grazing and iron limitation. We make the argument specific to an ocean area by taking the chemostat as an analogue for an equatorial upwelling zone. The chemostat analogy has been used to investigate the dynamics and control within several types of pelagic food chains (see Wright 1988), though the application here closely parallels that of Caperon (1975). 


\section{METHODS}

Physical setting. The physical setting for the model is the mixed layer of an equatorial upwelling zone, such as that in the eastern equatorial Pacific to the west of the Galapagos Islands. Between longitudes $90^{\circ}$ and $130^{\circ} \mathrm{W}$ upwelling supplies dissolved nutrients to the surface layer. For a $30 \mathrm{~m}$ mixed layer at the equator, an upwelling rate of about 1 to $2 \mathrm{~m} \mathrm{~d}^{-1}$ into the mixed layer (Philander 1990) corresponds to an advective throughput rate of about 0.033 to $0.066 \mathrm{~d}^{-1}$. The upwelled water is redistributed meridionally and zonally (Bender \& McPhaden 1990).

Chemostat analogue. Consider a nitrogen-limited chemostat with 11 liquid volume which has an inflow rate $(\delta)$ set at $0.033 \mathrm{ld} \mathrm{d}^{-1}$, thus approximating the advection of nutrients into and out of the mixed layer at the equator. A planktonic food chain within the chemostat contains i to 4 trophic types: phytopiankton or autotroph $(\mathrm{A})$, herbivore $(\mathrm{H})$, primary carnivore $\left(\mathrm{C}_{1}\right)$, and secondary carnivore $\left(\mathrm{C}_{2}\right)$. Phytoplankton population growth depends only on nutrient concentration (nitrogen unless otherwise specified), grazing mortality and outflow from the chemostat; light is assumed non-limiting. Maximum specific growth rate of the phytoplankton is set at $1.4 \mathrm{~d}^{-1}$, as determined by temperature and light conditions in the equatorial Pacific upwelling zone (see Banse in press)

As a minimal simple representation of the dynamics of a consumer type, prey is ingested in density-dependent fashion and converted to new body substance with $40 \%$ efficiency; the consumer excretes (regenerates) dissolved nitrogen equivalent to $30 \%$ of its ingested food, and experiences loss in the outflow from the chemostat. For simplicity of analysis and interpretation, it is first assumed that the phytoplankton make no distinction between available forms of dissolved $\mathrm{N}$ (e.g. nitrate and ammonium); the consequences of this assumption will be examined in a subsequent section. The equations governing the concentrations of phytoplankton, consumers and nutrient are:

$$
\begin{aligned}
& \frac{\mathrm{d} A}{\mathrm{~d} t}=A\left[\frac{\alpha(N)}{\beta+N}-\delta\right]-H \frac{\gamma_{h}(A-\theta)}{\varepsilon_{\mathrm{h}}+H-\bar{\theta}} \\
& \frac{\mathrm{d} H}{\mathrm{~d} t}=H\left[\frac{0.4 \gamma_{\mathrm{h}}(A-\theta)}{\varepsilon_{\mathrm{h}}+A-\theta}-\delta\right]-C_{1} \frac{\gamma_{1}(H-\theta)}{\varepsilon_{1}+H-\theta} \\
& \frac{\mathrm{d} C_{1}}{\mathrm{~d} t}=C_{1}\left[\frac{0.4 \gamma_{1}(H-\theta)}{\varepsilon_{1}+H-\theta}-\delta\right]-C_{2} \frac{\gamma_{2}\left(C_{1}-\theta\right)}{\varepsilon_{2}+C_{1}-\theta} \\
& \frac{\mathrm{d} C_{2}}{\mathrm{~d} t}=C_{2}\left[\frac{0.4 \gamma_{2}\left(C_{1}-\theta\right)}{\varepsilon_{2}+C_{1}-\theta}-\delta\right]
\end{aligned}
$$

$$
\begin{aligned}
\frac{\mathrm{d} N}{\mathrm{~d} t}= & -A \frac{\alpha(N)}{\beta+N}+H \frac{0.3 \gamma_{\mathrm{h}}(A-\theta)}{\varepsilon_{\mathrm{h}}+A-\theta}+C_{1} \frac{0.3 \gamma_{1}(H-\theta)}{\varepsilon_{1}+H-\theta} \\
& +C_{2} \frac{0.3 \gamma_{2}\left(C_{1}-\theta\right)}{\varepsilon_{2}+C_{1}-\theta}+\delta\left(N_{0}-N\right)
\end{aligned}
$$

Variables and parameters are defined in Table 1. Standing stocks of the trophic levels are calculated as particulate organic nitrogen, but in the figures below phytoplankton stock has been converted to chlorophyll $a(1 \mu \mathrm{g} \mathrm{chl} a=8.77 \mu \mathrm{g} \mathrm{N}$ i i.e. C: $\operatorname{chl} a=50)$.

Table 1. Significant symbols used in the model. Values for the feeding threshold $(\theta)$ and half-saturation constant for ingestion (c) were based on Heinbokel's (1978) results for the tintinnid ciliate Eutintinnus pectinis. Other parameter values are explained in the text

Biological and chemical variables

A Phytoplankton or autotroph standing stock $\left(\mu \mathrm{gN} \mathrm{l}^{-1}\right)$

$H \quad$ Herbivore standing stock $\left(\mu g \mathrm{~N}^{-1}\right)$

$C_{1}, C_{2}$ Primary and secondary carnivore standing stock $\left(\mu \mathrm{NN} \mathrm{l}^{-1}\right)$

$N \quad$ Nutrient (nitrogen) concentration in chemostat $\left.(\mu \mathrm{mol} \mathrm{N}]^{-1}\right)$

\section{Parameters}

$\alpha \quad$ Phytoplankton maximum specific growth rate $\left(1.4 \mathrm{~d}^{-1}\right)$

$\beta \quad$ Hall-saturation constant for phytoplankton nitrogen uptake $\left(0.5 \mu \mathrm{mol} \mathrm{N} 1^{-1}\right)$

$\gamma_{n}, \gamma_{1}, \gamma_{2}$ Maximum specific ingestion rate for $\mathrm{H}\left(1.4 \mathrm{~d}^{-1}\right)$, $C_{1}\left(0.7 \mathrm{~d}^{-1}\right)$, and $C_{2}\left(0.35 \mathrm{~d}^{-1}\right)$

$\delta \quad$ Dilution rate for the chemostat $\left(0.033 \mathrm{~d}^{-1}\right)$

$\varepsilon_{\mathrm{h}} \varepsilon_{1}, \varepsilon_{2}$ Half-saturation constant for ingestion rate of $\mathrm{H}$ $\mathrm{C}_{1}$, and $\left.\mathrm{C}_{2}(2.9 \mu \mathrm{gN})^{1}\right)$

$\theta \quad$ Feeding threshold for $\mathrm{H}, \mathrm{C}_{1}$, and $\mathrm{C}_{2}\left(1.8 \mu \mathrm{gN} \mathrm{l}^{-1}\right)$

$N_{0} \quad$ Nutrient (nitrogen) concentration in inflow to chemostat $\left(10.0 \mu \mathrm{mol} \mathrm{N} \mathrm{^{-1 }}\right)$

A food chain of 4 trophic levels within a chemostat may strain credulity, but one can certainly identify specific types of protists that are herbivores and primary carnivores (e.g. heterotrophic flagellates and suspensionfeeding ciliates or heterotrophic dinoflagellates). The secondary carnivore could also be a protist (e.g. the ciliates Didinium or Tontonid; see Fenchel 1987 for other examples). Thus Eqs. (2) to (4) are plausible representations of the population dynamics of the 3 consumer types. It is reasonable to assume that the 3 consumers differ in size (herbivore<primary carnivore<secondary carnivore) and that their maximum specific ingestion rate $(\gamma)$ decreases in proportion to their size. Thus, taking maximum specific ingestion rate of the herbivore $\left(\gamma_{h}\right)$ at $1.4 \mathrm{~d}^{-1}$ (likely a conservative value), the rates for the primary and 
secondary carnivore are set at $1 / 2$ and $1 / 4$ that value. However, for want of information, the feeding threshold $(\theta)$ and half-saturation constants for ingestion $(\varepsilon)$ are identical for the 3 consumer types (Table 1).

Also because of lack of information, particularly on consumers, it was assumed that upwelling water contains only nutrients and no organisms. However, the euphotic zone is much deeper than the mixed layer in the equatorial upwelling zone and substantial concentrations of phytoplankton exist below the mixed layer (Chavez et al. 1990, Peña et al, 1990, Cullen et al. 1992). Consumer populations must be there as well. The effect of excluding organisms from the inflow will be examined.

The equations were solved numerically over hourly time steps. Although the steady state solution can be obtained directly (Caperon 1975), a predicted time course to steady state will be of interest for various reasons, and is illustrated for several cases. This time course depends on initial conditions. For all simulations of the chemostat model the initial concentration of phytoplankton was $0.25 \mu \mathrm{g} \mathrm{chl} \mathrm{a} \mathrm{l}^{-1}$ and the initial concentration of nutrient was $7 \mu \mathrm{mol} \mathrm{N}^{-1}$, corresponding to approximate mean conditions in the Pacific equatorial upwelling zone at $120^{\circ} \mathrm{W}$ (Chavez et al. 1990). The nutrient concentration in the inflow to the

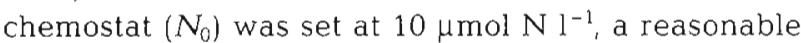
value for just below the mixed layer (Chavez et al. 1990). Lacking information, the initial standing stocks of consumers were arbitrarily set at $2 \mu \mathrm{g} \mathrm{N} 1^{-1}$.

\section{RESULTS}

\section{General features of nutrient limitation}

With only phytoplankton in the chemostat i.e. $H=$ $C_{1}=C_{2}=0$ ) the phytoplankton rapidly blooms, depleting the nutrient, then gradually approaches a high steady state concentration (Fig. 1). Steady state specific growth rate of the phytoplankton and concentrations are given by

$$
\begin{gathered}
\frac{\alpha(N)}{\beta+N}=\delta \\
N=\frac{\beta \delta}{\alpha-\delta} \\
A=N_{0}-\frac{\beta \delta}{\alpha-\delta}
\end{gathered}
$$

Consistent with chemostat theory (Herbert et al. 1956) the specific growth rate of the phytoplankton at steady state is determined by the dilution rate of the chemostat (Eq. 6a), while phytoplankton standing stock depends directly on the concentration of nitrogen

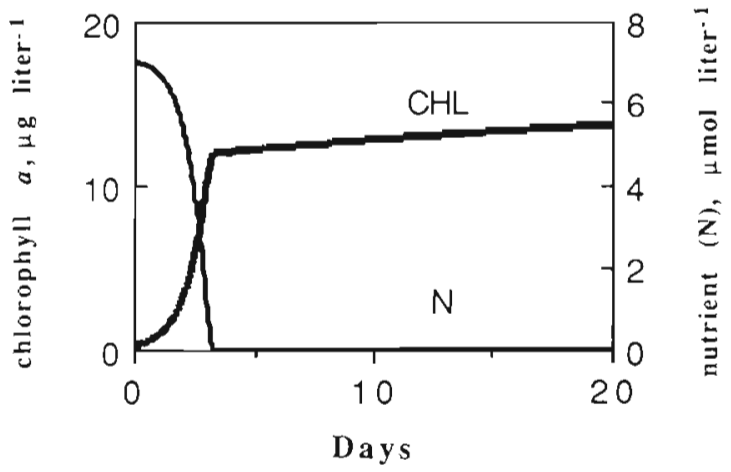

Fig. 1. Phytoplankton standing stock (CHL) and nitrogen concentration $(N)$ in a chemostat containing only phytoplankton and with nitrogen as the limiting nutrient. Predicted steady state concentrations (Eqs. 6b, c) are $15.94 \mu \mathrm{g} \mathrm{chl} \mathrm{a} \mathrm{l}^{-1}$ and

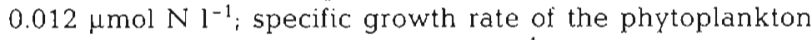
(Eq. 6a) is $0.033 \mathrm{~d}^{-1}$

in the inflow (Eq. 6c). Thus, doubling $N_{0}$ approximately doubles $A$, but does not change the specific growth rate. Doubling $\delta$ has little effect on $A$, but doubles the specific growth rate of the phytoplankton. However, at any $\delta$ approximating the upwelling rate in the equatorial upwelling zone ( 1 to $2 \mathrm{~m} \mathrm{~d}^{-1}$; see 'Methods'), the specific growth rate is very low $\left(0.033\right.$ to $\left.0.066 \mathrm{~d}^{-1}\right)$. Adding phytoplankton to the inflow (at a concentration of $0.25 \mu \mathrm{g}$ chl a $\mathrm{l}^{-1}$ ) had a very minor effect, merely accelerating the bloom slightly.

At steady state the combination of high phytoplankton concentration and low nutrient concentration (Fig. 1) is the inverse of that observed in the Pacific equatorial upwelling zone. Grazing can remedy this, but before considering the effect of grazing it is useful to look at how micronutrient limitation alone (as proposed by Martin et al. 1989) might account for the observed pattern.

It is straightforward to consider a second dissolved nutrient, say phosphorus, and determine concentrations of nutrients and phytoplankton as the ratio $\mathrm{N}: \mathrm{P}$ is varied in the inflow. Assume the average Redfield ratio (Redfield et al. 1963) for cellular N : P in phytoplankton (16:1 by atoms or 7.2:1 by weight). Also assume that the half-saturation constant for phosphorus uptake by the phytoplankton $\left(\beta_{\mathrm{P}}\right)$ is $0.03125 \mu \mathrm{mol} \mathrm{P}^{-1}$, i.e. exactly in proportion to Redfield ratio for $\mathrm{N}: \mathrm{P}$ by atoms. Then if $N$ and $P$ are supplied in the ratio $16: 1$ in the inflow to the chemostat, the chemostat model prediction is identical to that in Fig. 1.

However, if nitrogen and phosphorus are supplied in ratios greater than $16: 1$, then phosphorus will be the limiting nutrient and its concentration in the inflow will determine the steady state concentration of phytoplankton in the chemostat. Fig. 2 shows the model predictions for the previous case $(\mathrm{N}: \mathrm{P}=16: 1)$ and for 

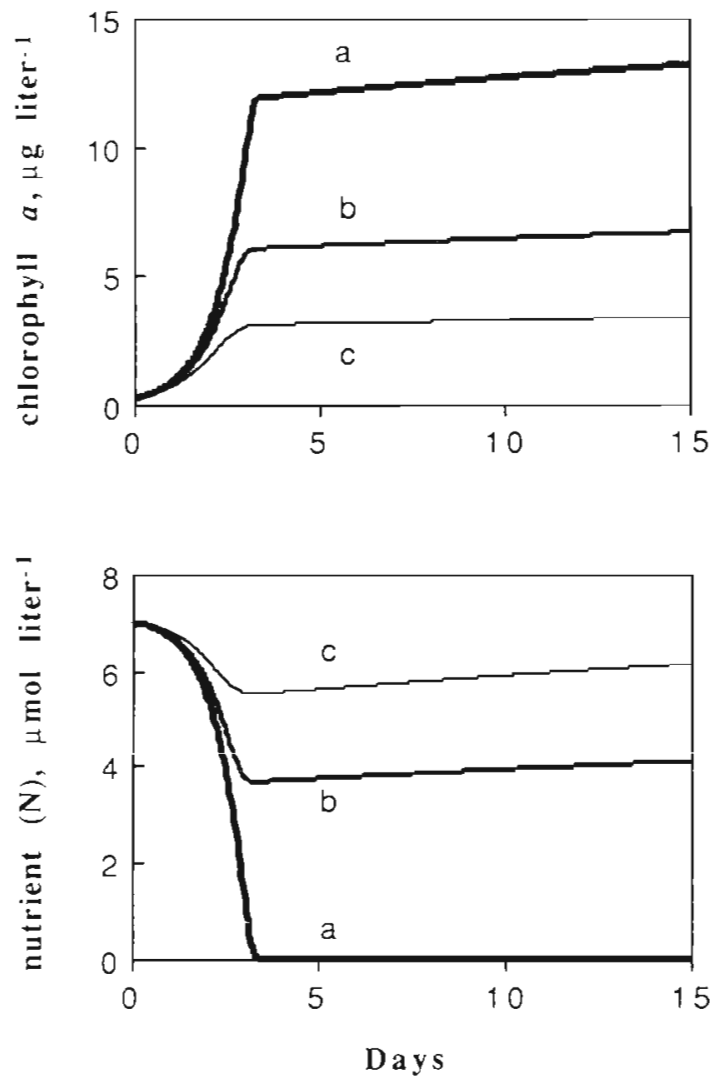

Fig. 2. Phytoplankton standing stock and nitrogen concentration in a chemostat containing only phytoplankton and with both nitrogen $(N)$ and phosphorus $(P)$ in the inflowing nutrient medium. Illustrated are cases in which the nutrient medium flowing into the chemostat has $\mathrm{N}$ : $\mathrm{P}$ by atoms: (a) $16: 1$, (b) $32: 1$, and (c) $64: 1$

cases in which nitrogen and phosphorus are supplied in the ratios $32: 1$ and $64: 1$ (i.e. at 2 and 4 times the Redfield ratio). As the $\mathrm{N} \cdot \mathrm{P}$ ratio increases from the Redfield ratio the phytoplankton concentration at steady state decreases and nitrogen is no longer depleted. Clearly, further divergence of $\mathrm{N}$ : P of inflowing nutrients from the Redfield ratio will give even lower steady state concentration of phytoplankton. Eqs. $(6 \mathrm{~b}, \mathrm{c})$ specify that with $\mathrm{N}: \mathrm{P}$ of inflowing nutrients in the molar ratio of 10:0.01054 (i.e. 59.3 times the Redfield ratio) and a phosphorus concentration of $0.00075 \mu \mathrm{mol} \mathrm{l}^{-1}$ in the chemostat, the phytoplankton stock remains at a constant, very low concentration (Fig. 3A)

It follows logically from this analysis with phosphorus that if nitrogen and an essential micronutrient such as dissolved iron are supplied in the chemostat inflow at ratios greater than their ratio in phytoplankton cells, then that micronutrient will become limiting and $\mathrm{N}$ (as well as other essential nutrients) will remain high and phytoplankton stock will be low, just as
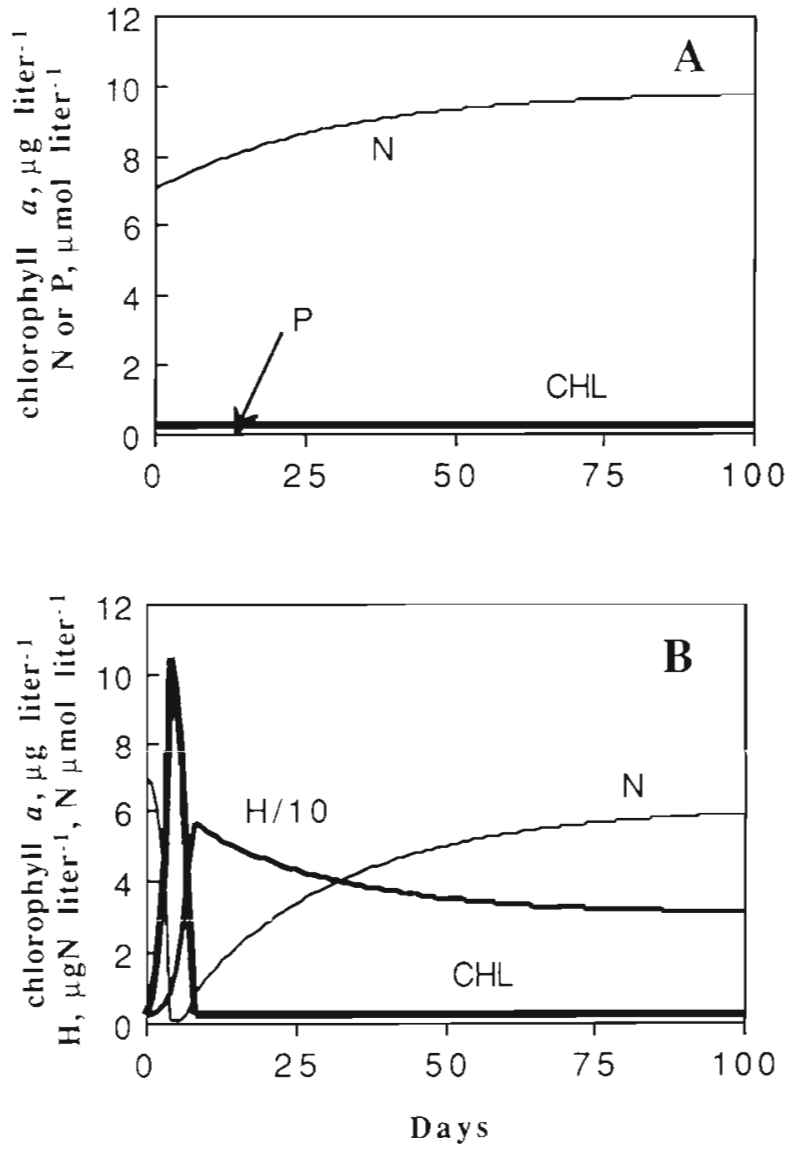

Fig. 3. (A) Phytoplankton standing stock (CHL) and nutrient concentration in a chemostat containing only phytoplankton and with both nitrogen $(N)$ and phosphorus $(P)$ in the inflowing nutrient medium. The nutrient medium flowing into the chemostat has $\mathrm{N}: \mathrm{P}=10: 0.01054$ by atoms and initial nutrient

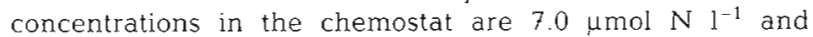
$0.00075 \mu \mathrm{mol} \mathrm{P}^{-1}$ (B) Predictions for phytoplanktonherbivore chemostat with nitrogen as the limiting nutrient. Initial standing stock of herbivore is $2 \mu \mathrm{gN}^{-1}$. Note that although steady state concentrations of phytoplankton are similar in (A) and (B), and nitrogen concentrations are high, the phytoplankton specific growth rates are very different: $0.033 \mathrm{~d}^{-1}$ (A) vs $1.294 \mathrm{~d}^{-1}$ (B)

Martin et al. (1989) have proposed for several nutrientrich areas of the open sea. For example, Martin (1991) discussed measurements of dissolved iron made recently in the equatorial Pacific upwelling zone. Upwelling water was characterized as containing 0.01 nmol Fe $l^{-1}$ and $8.1 \mu \mathrm{mol} \mathrm{NO}_{3} \mathrm{l}^{-1}$ (i.e. an $\mathrm{N}$ : Fe ratio of $810000: 1$ ). Assume that the estimate of Sunda et al. (1991) for cellular $\mathrm{N}$ : Fe of an oceanic diatom species (75471:1 by atoms, with cellular $C N$ of 6.625 .1 ) is typical of phytoplankton species in the Pacific equatorial upwelling zone. In addition, assume that the half-saturation constant for uptake of Fe by phytoplankton is $6.625 \mathrm{pmol}^{-1}$, i.e. exactly in proportion to 
the cellular $\mathrm{N} \cdot \mathrm{Fe}$ by atoms in phytoplankton cells Then Eqs. $(6 \mathrm{~b}, \mathrm{c})$ indicate a steady state phytoplankton

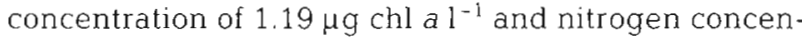
tration of $7.36 \mu \mathrm{mol} \mathrm{I}^{-1}$. The estimated phytoplankton concentration depends primarily on the concentration of $\mathrm{Fe}$ in the inflowing nutrient medium (Eq. 6C) and is little altered by changes in $\alpha, \beta$ (including $\beta=0$ ) and $\delta$ However, it also depends heavily on $\mathrm{N}: \mathrm{chl}$ a of phytoplankton cells. The value used here was $8.77 \cdot 1$ With a slightly larger value of $10.53: 1$, suggested by Barber \& Chavez (1991), the estimated steady state concentration of phytoplankton is $0.98 \mu \mathrm{g} \mathrm{chl} \mathrm{a} \mathrm{l}^{-1}$. These predicted phytoplankton concentrations are about 2.5 to 6 times greater than observed concentrations. Note that the predictions would fall in the range of observations with the smaller $\mathrm{N}$ : Fe ratio 19623:1 for coastal phytoplankton species used by Young et al. (1991): however, it seems likely that oceanic phytoplankton, being exposed to much lower concentrations of dissolved iron than coastal species (Martin et al. 1989), will have higher cellular $\mathrm{N}$ : Fe than coastal species (Sunda et al. 1991).

The problem with all of these scenarios is that the specific growth rate of the phytoplankton is exceedingly low, that is, equivalent to the inflow rate in the chemostat $\left(0.033 \mathrm{~d}^{-1}\right)$ or, in the case of the Pacific equatorial upwelling zone, to the advective throughput rate in the mixed layer. But phytoplankton specific growth rates in the equatorial Pacific are much higher than the replacement rate implied by the meridional advection rate (Barber \& Chavez 1991, Peña et al. 1991, Cullen et al. 1992). Moreover, the concentration of $\mathrm{Fe}$ in upwelling water is very low (Martin 1991). Thus, to account for the significant phytoplankton growth and production that is observed in the Pacific equatorial upwelling zone, Martin et al. (1989, 1991) and Martin (1991) were forced to hypothesize other sources for input of iron (i.e. input in atmospheric dust), a subject to be addressed below, but the alternative is that the standing stock of phytoplankton is low and its specific growth rate is high because of grazing control.

\section{General features of grazing control}

Returning to the model chemostat with a single limiting nutrient $(\mathrm{N})$, when both phytoplankton and a phytophagous protozoan species are included in the chemostat $\left(C_{1}=C_{2}=0\right)$, with initial concentrations phytoplankton and nitrogen as above and $2 \mu \mathrm{gN}^{-1}$ of the protistan grazer, the phytoplankton blooms briefly, then drops to very low concentration as the grazer population responds (Fig. 3B). The phytoplankton bloom occurs because of the arbitrarily set initial stock of herbivore, which turned out to be well below the steady state value. Information on herbivore standing stocks in the mixed layer of the equatorial upwelling zone will be required to better constrain initial conditions for the model. For example, if initial herbivore stock is increased to just $25 \%$ of the steady state value in Fig 3B, the phytoplankton bloom is suppressed and the nutrient concentration remains high. Adding phytoplankton and herbivores to the inflow does not alter the above results in any significant way. Thus, initial conditions in the mixed layer are of crucial importance to the model predictions, but not interactions between phytoplankton and herbivores that may take place in the portion of the euphotic zone below the mixed layer.

That the phytoplankton standing stock is controlled chiefly by grazing is demonstrated by solving Eq. 2 $\left(C_{1}=0\right)$ for steady state:

$$
A=\frac{\varepsilon_{\mathrm{h}} \delta}{0.4 \gamma_{\mathrm{h}}-\delta}+\theta
$$

Only grazing parameters and dilution rate $(\delta)$ appear in the equation, and for any realistic value of $\delta$ for the equatorial upwelling zone, the herbivore feeding threshold $(\theta)$ is the dominant factor. Phytoplankton specific growth rate as well as the concentrations of the herbivore and nutrient are more complicated functions whose dependence on $N_{0}$ and $\delta$ were investigated by numerical solution of the model. Increase and decrease of $N_{0}$ by $50 \%$ is reflected chiefly in increased and decreased nutrient concentration in the chemostat, with much smaller ( $<17 \%$ ) changes in phytoplankton specific growth rate and herbivore standing stock (Table 2). Halving or doubling $\delta$ has a marked effect on herbivore standing stock, as expected since $\delta$ determines the mortality rate of the herbivore, but considerably less influence on phytoplankton stock and specific growth rate (Table 2). These changes demonstrate that under grazing control phytoplankton standing stock can be about the same despite very different upwelling rates and nutrient concentrations (Table 2), just as observed along the equator in the eastern equatorial Pacific (Chavez et al, 1990). Over a broad range of realistic values for all parameters $[\alpha, \beta$ (including $\beta=0$ ), $\gamma_{\mathrm{h}}, \theta(>0), \delta$, and $N_{0}$ ) the model produces a stable equilibrium point in $A, H$, and $N$ at steady state.

This simple example (Fig. 3B) dramatically illustrates how grazing control of phytoplankton stock could produce the conditions of high nutrients and low phytoplankton stock, together with high specific growth rate of the phytoplankton [1.29 $\mathrm{d}^{-1}$ (Table 2 ) or $92 \%$ of the maximum value]. This combination of conditions is at least qualitatively like that observed in the Pacific equatorial upwelling zone. By contrast, in the case of severe nutrient limitation (Fig. 3A) only 2 of the 3 observed conditions are reproduced, the specific 
Table 2. Effect of $N_{0}$ and $\delta$ on steady state conditions in a chemostat containing phytoplankton and herbivore. CHL: phytoplankton standing stock as $\mu \mathrm{g}$ chl a $\mathrm{l}^{-1} ; \mu$ : phytoplankton specific growth rate $\left(d^{-1}\right)=\alpha N /(\beta+N)$. Fig. $3 B$ illustrates the case $N_{0}=10, \delta=0.033$

\begin{tabular}{rlrrrr|}
\hline$N_{0}$ & \multicolumn{1}{c}{$\delta$} & $C H L$ & $H$ & $N$ & $\mu$ \\
\hline 5 & 0.033 & 0.23 & 25.22 & 1.71 & 1.083 \\
10 & 0.033 & 0.23 & 30.28 & 6.07 & 1.294 \\
15 & 0.033 & 0.23 & 31.36 & 10.94 & 1.339 \\
10 & 0.0165 & 0.22 & 54.35 & 3.07 & 1.204 \\
10 & 0.033 & 0.23 & 30.28 & 6.07 & 1.294 \\
10 & 0.066 & 0.25 & 16.56 & 7.77 & 1.315 \\
\hline
\end{tabular}

growth rate of the phytoplankton being extremely low (determined by dilution rate of the chemostat). Thus, the alternative mechanisms of control of phytoplankton stock (nutrient limitation vs grazing) are clearly juxiaposed in Fig. 3

Although grazing control accounts best for the high nutrient-low phytoplankton stock phenomenon, this model is still too simple to account quantitatively for observed nutrient concentrations and possibly for the observed phytoplankton specific growth rates. Two elaborations of the model permit identification of the probable underlying mechanisms.

\section{Effect of $\mathrm{N}$ recycling on nitrate and ammonium concentration}

In the preceding analysis it was assumed that in their utilization of the dissolved nutrient $N$ phytoplankton make no distinction between available forms of $\mathrm{N}$. It can be shown that at steady state a significant fraction $(14.0 \%)$ of $\mathrm{N}$ in the chemostat with phytoplankton and herbivores (Fig. 3B) derives from recycling via herbivore excretion. Based on this percentage the $f$-ratio (fraction of total $N$ uptake supplied by inflowing or 'new' $N$ ) predicted by the model is very high $(0.86)$ in comparison with the $f$-ratio estimated for the Pacific equatorial upwelling zone (0.44, Eppley 1989; but see below). Since preferential utilization of recycled $\mathrm{N}$ by phytoplankton. would decrease the $f$-ratio, thereby influencing the concentration of nitrate as well, this effect could be important for understanding the relative concentrations of new and recycled nutrients. We merely wish to show that the effect is readily represented in the model. To do so requires explicit accounting of both new and recycled nutrients and how they individually affect phytoplankton growth, together with a more complete description of nitrogen recycling, including a source for recycled $\mathrm{N}$ besides excretion by herbivores (King 1987). That additional source is assumed to be release of ammonium from detritus.
In the chemostat with phytoplankton and herbivore, a detrital compartment can be construed as consisting of the particulate fecal debris produced during egestion by herbivores. Assume that detritus is not reingested by herbivores, but that a fraction of detrital $N$ is released at rate $\lambda \mathrm{d}^{-1}$ back into dissolved form as ammonium. Then based on Eq. $2\left(C_{1}=0\right)$ the concentration of detritus in the chemostat $\left(D, \mu \mathrm{gN} \mathrm{l}^{-1}\right)$ may be governed by 3 processes:

$$
\frac{\mathrm{d} D}{\mathrm{~d} t}=0.3\left(H \frac{\gamma_{\mathrm{h}}(A-\theta)}{\varepsilon_{\mathrm{h}}+A-\theta}\right)-D(\delta+\lambda)
$$

where the factor 0.3 is the fraction of food ingested by herbivores that is not utilized in their growth and excretion. Thus, detrital $\mathrm{N}$ is not supplied in the inflow.

Dissolved inorganic nitrogen is assumed to be available to the phytoplankton as nitrate and ammonium; other forms of recycled $N$ (e.g. urea) are not distinguished from ammonium. Input of nitrate to the chemostat is solely via the inflow, whereas ammonium has 3 sources: the inflow, excretion by herbivores, and release from detritus. Ammonium may inhibit utilization of nitrate or may at least be preferentially utilized by the phytoplankton, though the exact nature of the interaction is uncertain (Dortch 1990). To explore the effect in the model an interaction analogous to noncompetitive inhibition of enzyme activity (Price \& Stevens 1982) is introduced. Eqs. (1) and (5) are thus madified to describe changes in concentration of phytoplankton, nitrate and ammonium in the chemostat:

$$
\begin{aligned}
\frac{\mathrm{d} A}{\mathrm{~d} t}= & A\left[\alpha\left(\frac{N O_{3}}{\beta_{\mathrm{NO}_{3}}+N O_{3}} \frac{1}{1+\frac{N H_{4}}{k}}+\frac{N H_{4}}{\beta_{\mathrm{NH}_{4}}+N H_{4}}\right)-\delta\right] \\
& -H \frac{\gamma_{\mathrm{h}}(A-\theta)}{\varepsilon_{\mathrm{h}}+A-\theta}
\end{aligned}
$$

$$
\begin{aligned}
\frac{\mathrm{d} N O_{3}}{\mathrm{~d} t}= & -A \alpha\left(\frac{N O_{3}}{\beta_{\mathrm{NO}}+N O_{3}} \frac{1}{1+\frac{N H_{4}}{\kappa}}\right) \\
& +\delta\left(\left[\mathrm{NO}_{3}\right]_{0}-N O_{3}\right)
\end{aligned}
$$

$$
\begin{aligned}
\frac{\mathrm{d} N H_{4}}{\mathrm{~d} t}= & -A \alpha\left(\frac{N H_{4}}{\beta_{N H_{4}}+N H_{4}}\right)+0.3\left(H \frac{\gamma_{\mathrm{h}}(A-\theta)}{\varepsilon_{\mathrm{h}}+A-\theta}\right) \\
& +\lambda D+\delta\left(\left[N H_{4}\right]_{0}-N H_{4}\right)
\end{aligned}
$$

where $\beta_{\mathrm{NO}_{3}}$ and $\beta_{\mathrm{NH}_{4}}$ are half-saturation constants for uptake of nitrate and ammonium $\left(0.5\right.$ and $0.1 \mu \mathrm{mol} \mathrm{l}^{-1}$. respectively): $\kappa$ is an inhibition constant $(0.1 \mu \mathrm{mol}$. $\left.\left.\mathrm{NH}_{4}\right]^{-1}\right]_{;}$and $\left[\mathrm{NO}_{3}\right]_{0}$ and $\left[\mathrm{NH}_{4}\right]_{0}$ are nutrient concentrations in the inflowing medium; $\left[\mathrm{NO}_{3}\right]_{0}=10 \mu \mathrm{mol} \mathrm{l}^{-1}$ as before, $\left.\left[\mathrm{NH}_{4}\right]_{0}=0.3 \mu \mathrm{mol}\right]^{-1}$ as observed just below the mixed layer in the equatorial Pacific upwelling zone between 110 and $140^{\circ} \mathrm{W}$ (F. Chavez pers comm.). A non-competitive inhibition was chosen to 
describe the effect of ammonium concentration on nitrate uptake rather than, for example, the scheme of Fasham et al. (1990), for 2 reasons. First, in the natural range of nutrient concentrations and for $\kappa \leq 0.1$ the phytoplankton specific growth rate $(\mu)$

$\mu=\alpha\left(\frac{N O_{3}}{\beta_{\mathrm{NO}_{3}}+N O_{3}} \frac{1}{1+\frac{N H_{4}}{\kappa}}+\frac{N H_{4}}{\beta_{\mathrm{NH}_{4}}+N H_{4}}\right)$

has a maximum value $\alpha$. Second, for a given concentration of nitrate the phytoplankton specific growth rate increases with increasing concentration of ammonium.

In simulations using this modified model [Eqs. $2\left(C_{1}\right.$ $=0)$ and $(8)$ to $(11)]$ the initial concentrations of organisms were as before (Fig. 3B). Initial concentration of nitrate was $7 \mu \mathrm{mol} \mathrm{l}^{-1}$ and that for ammonium was $0.2 \mu \mathrm{mol} 1^{-1}$. The initial concentration of detritus was zero. At steady state the model satisfies the condition

$$
A+H+D+N O_{3}+N H_{4}=\left[N_{3}\right]_{0}+\left[N H_{4}\right]_{0}
$$

where nutrient concentrations are converted to their mass equivalents and $\left[\mathrm{NO}_{3}\right]_{0}+\left[\mathrm{NH}_{4}\right]_{0}=144.2 \mu \mathrm{g} \mathrm{N} \mathrm{l^{-1 }}$. The $f$-ratio is now defined as it is usually measured (Eppley 1989), i.e. $\mathrm{NO}_{3}$ uptake/( $\mathrm{NO}_{3}$ uptake $+\mathrm{NH}_{4}$ uptake); note, however, that $\mathrm{NH}_{4}$ uptake includes some ammonium derived from the inflow.

In Table 3 the steady state predictions of the modified $N$-recycling model are given for 3 cases, together with the results of the previous version of the chemostat with phytoplankton and herbivore (Fig. 3B). In Case 1 detritus was not recycled $(\lambda=0)$, whereas in

Table 3. Steady state predictions for the chemostat with phytoplankon and herbivore. Cases 1 to 3 refer to the modified model [Eqs. $2\left(C_{1}=0\right)$ and (8) to (11)] explicitly describing detritus, nitrate and ammonium (Case 1, $\lambda=0$; Case 2, $\lambda=$ $0.1 \mathrm{~d}^{-1}$; Case $3, \lambda=0.2 \mathrm{~d}^{-1}$. CHL: phytoplankton standing stock as $\mu \mathrm{g}$ chl a $\mathrm{l}^{-1} ; D$ : concentration of detritus; $\mu$ : phytoplankton specific growth rate $\left(\mathrm{d}^{-1}\right)$ calculated from Eq. (12) (Cases 1 to 3 ) or as in Table 2. The result from Fig. 3B is presented for comparison

\begin{tabular}{|c|c|c|c|c|}
\hline & Case 1 & Case 2 & Case 3 & Fig. 3B \\
\hline CHL & 0.23 & 0.23 & 0.23 & 0.23 \\
\hline$H$ & 31.13 & 31.83 & 31.91 & 30.28 \\
\hline$D$ & 23.35 & 5.92 & 3.39 & $22.71^{\circ}$ \\
\hline $\begin{array}{l}\mathrm{NO}_{3} \\
\mathrm{NH}_{4}\end{array}$ & $\begin{array}{l}6.22 \\
0.047\end{array}$ & $\begin{array}{l}7.35 \\
0.112\end{array}$ & $\begin{array}{l}7.51 \\
0.126\end{array}$ & $6.07^{b}$ \\
\hline$\mu$ & 1.33 & 1.36 & 1.36 & 1.30 \\
\hline$f$-ratio & 0.66 & 0.46 & 0.43 & $0.86^{\circ}$ \\
\hline \multicolumn{5}{|c|}{$\begin{array}{l}\text { a By difference, where concentrations of all forms of } \mathrm{N} \text { in } \\
\text { chemostat }=\mathrm{N}_{0} \\
\text { b Includes both 'new' }(86.0 \%) \text { and recycled } \mathrm{N}(14.0 \%) \\
\text { 'Based on fraction of dissolved nutrient } \mathrm{N} \text { that is 'new' }\end{array}$} \\
\hline
\end{tabular}

Cases 2 and 3 detritus was recycled at relatively high rates $\left(\lambda=0.1\right.$ and $\left.0.2 \mathrm{~d}^{-1}\right)$. In Cases 1 to 3 predicted concentrations of organisms differ in no substantial way from the results of the simpler model in Fig. $3 B$, but when detritus is recycled $(\lambda \geq 0.1)$ the range of $f$ ratio now includes the estimate for the Pacific equatorial upwelling zone (0.44: Eppley 1989). As the rate of release of ammonium from detritus is increased, concentrations of both ammonium and nitrate increase and the $f$-ratio decreases. Some much lower estimates of $f$-ratio in the central Pacific equatorial upwelling zone (Price et al. 1991, Dugdale et al. 1992) clearly imply even greater recycling of $N$ than is possible with the model containing only phytoplankton and herbivores. Experiments (not reported here) with the full model, containing all 3 consumer types and modified along the lines of Eqs. (8) to (11), yielded lower $f$-ratios with sufficiently large values of $\lambda$.

These results suggest that both grazing control and some sort of preferential utilization of ammonium by the phytoplankton are required to explain the relative magnitudes of nitrate and ammonium concentration in the mixed layer of the equatorial Pacific upwelling zone. However, since standing stocks of organisms and phytoplankton specific growth rates are similar, and nutrient concentrations are high, with or without $\mathrm{N}$ differentiated (Table 3), for the remaining investigations reported below we return the simpler model with $\mathrm{N}$ undifferentiated. This simplification in no way affects the general conclusions.

\section{Simultaneous nutrient limitation and grazing control}

The maximum specific growth rate of the phytoplankton in the equatorial upwelling zone may be 1.4 $\mathrm{d}^{-1}$ (Banse in press). Highest observed specific growth rates are about $0.7 \mathrm{~d}^{-1}$ (Cullen et al. 1992), or about half of the maximum value, suggesting moderate depression of growth rate that might be due to limitation by nutrients other than nitrogen. That grazing control could act in concert with nutrient limitation to account for less than maximum specific growth rate is hinted in Table 2. Even with grazing control maintaining a relatively constant phytoplankton stock, the nutrient input rate, varied by changing $N_{0}$ or $\delta$, affects the phytoplankton specific growth rate ( $\mu$ in Table 2).

To examine the effect of simultaneous nutrient limitation and grazing control on specific growth rate of the phytoplankton, we introduce to the simpler model of the $\mathrm{N}$-limited chemostat with phytoplankton and herbivore (Eqs. (1), (2), and (5), with $C_{1}=C_{2}=0$ ] another nutrient that can potentially limit phytoplankton growth. Once again, let phosphorus be a surrogate for any such nutrient. Assume that $\mathrm{N}$ and $\mathrm{P}$ are utilized 
by both phytoplankton and grazers to maintain cellular $N: P$ in the Redfield ratio $(16: 1)$, and that both nutrients are also excreted (recycled) by the herbivore. As before, if nitrogen and phosphorus are provided in the chemostat inflow in ratios greater than their ratio in phytoplankton cells, then phosphorus limits phytoplankton growth. Some steady state solutions are shown in Table 4 for different $N$ : $P$ ratios of the inflowing nutrient medium. As the $\mathrm{N}: \mathrm{P}$ ratio in the inflow increases, the phytoplankton specific growth rate decreases and nitrogen concentrations increase, despite phytoplankton stock remaining constant due to grazing control. At $\mathrm{N}: \mathrm{P}=64: 1$ the specific growth rate of the phytoplankton is about half the maximum rate. The relevance of these results to the Pacific equatorial upwelling zone is uncertain, for it hinges on the magnitude of the observed phytoplankton specific growth rates compared with the maximum rate possible under opinal yrow ih conditions. Nevertheless, an additional role for limitation of phytoplankton growth rate by a trace nutrient is theoretically feasible within the framework of the grazing control model.

The analysis can now be extended to a much rarer trace nutrient such as iron. We use $\mathrm{N}: \mathrm{Fe}=810000: 1$ for the inflowing nutrient medium, where $\mathrm{N}_{0}=8.1 \mu \mathrm{mol} \mathrm{l}^{-1}$ and $\mathrm{Fe}_{0}=10.0 \mathrm{pmol}^{-1}$ (Martin 1991), and Sunda et al.'s (1991) estimate of $75471: 1$ for $\mathrm{N}$ : Fe in phytoplankton cells. As before, we assume that the half-saturation constant for uptake of Fe by phytoplankton is $6.625 \mathrm{pmol} \mathrm{I}^{-1}$, i.e. exactly in proportion to the cellular $\mathrm{N}$ : Fe by atoms in phytoplankton cells. We also assume that Fe is recycled by herbivores in the same fashion as they recycle $\mathrm{N}$. In the steady state solution of the model (Table 5A, left column) phytoplankton stock is low, being controlled by grazing, and nitrogen concentration is high. The concentration of limiting nutrient ( $\mathrm{Fe}$ ) is very low, $1.16 \mathrm{pmol}$ $\mathrm{l}^{-1}$; this is well below the detection limit as observed

Table 4. Steady state predictions for the chemostat model with phytoplankton and herbivore [Eqs. (1), (2) and (5), with $C_{1}=C_{2}=0$ l and with both nitrogen and phosphorus in the inflowing nutrient medium. (N:P): ratio of nitrogen to phosphorus in the inflow to the chemostat $\left(N_{0}=10 \mu \mathrm{mol} \mathrm{l} l^{-1}\right.$ in all cases); $C H L$ : phytoplankton standing stock as $\mu \mathrm{g}$ chl $a \mathrm{I}^{-1}$, $\mu$ : phytoplankton specific growth rate $\left(\mathrm{d}^{-1}\right)=\alpha P /\left(\beta_{\mathrm{P}}+P\right)$. where $P$ is phosphorus concentration $\left(\mu \mathrm{mol} 1^{-1}\right)$ and $\beta_{P}=$ $0.03125 \mu \mathrm{mol} \mathrm{P}^{-1}$ Note that both $\mathrm{N}$ and $\mathrm{P}$ are recycled in herbivore excretion

\begin{tabular}{|lrrr|}
\hline & & $N: P$ & \\
& $16: 1$ & $32: 1$ & $64: 1$ \\
\hline$C H L$ & 0.23 & 0.23 & 0.23 \\
$H$ & 30.28 & 25.21 & 15.23 \\
$N$ & 6.07 & 6.71 & 7.95 \\
$P$ & 0.38 & 0.11 & 0.03 \\
$\mu$ & 1.29 & 1.08 & 0.67 \\
\hline
\end{tabular}

Table 5. Steady state predictions of the chemostat model for an iron limitation scenario suggested by Martin (1991) for the equatorial Pacific upwelling zone. The inflowing nutrient medium contains nitrogen $(N)$ and dissolved iron $(\mathrm{Fe})$ in the ratio $810000: 1\left(N_{0}=8.1 \mu \mathrm{mol} \mathrm{l^{-1 }}\right) . F e, F e_{0}$ : concentration of iron $\left(\mathrm{pmol} \mathrm{l}^{-1}\right)$ in the chemostat and in the inflowing nutrient medium. Cellular N : Fe in phytoplankton is $75471: 1$ (Sunda et al. 1991). (A) Predictions for the chemostat containing phytoplankton and herbivore [Eqs. (1), (2) and (5), with $\left.C_{1}=C_{2}=0\right)$. (B) Predictions for the chemostat containing only phytoplankton (Eqs. 6a, b, c). CHL: phytoplankton standing stock as $\mu \mathrm{g}$ chl a $1^{-1} ; \mu$ : phytoplankton specific growth rate $\left\{d^{-1}\right\}=\alpha F e /\left\{\beta_{\mathrm{Fe}}+F e\right)$, where $\beta_{\mathrm{Fe}}=6.625 \mathrm{pmol} \mathrm{Fe}^{-1}$. Note that both $\mathrm{N}$ and $\mathrm{Fe}$ are recycled in herbivore excretion

\begin{tabular}{|lccc|} 
& $\begin{array}{c}\delta=0.033 \\
F e_{0}=10.0\end{array}$ & $\begin{array}{c}\delta=0.066 \\
F e_{0}=10.0\end{array}$ & $\begin{array}{c}\delta=0.033 \\
F e_{0}=20.0\end{array}$ \\
& & $\mathbf{A}$ & \\
$\mathrm{CHL}$ & 0.23 & 0.25 & 0.23 \\
$H$ & 4.21 & 3.54 & 9.24 \\
$N$ & 7.43 & 7.50 & 6.80 \\
$F e$ & 1.16 & 2.07 & 2.82 \\
$\mu$ & 0.208 & 0.333 & 0.418 \\
& & & \\
$\mathrm{CHL}$ & 1.19 & $\mathbf{B}$ & \\
$N$ & 7.36 & 1.17 & 2.39 \\
$F e$ & 0.16 & 7.37 & 6.60 \\
$\mu$ & 0.033 & 0.33 & 0.16 \\
& & 0.066 & 0.033 \\
\hline
\end{tabular}

by Martin (1991) in the Pacific equatorial upwelling zone. The specific growth rate of the phytoplankton is quite low, substantially lower than the highest observed rates, and only about $15 \%$ of the possible maximum growth rate. The specific growth rate would be still lower if $\mathrm{Fe}$ was not recycled by herbivores or if $\mathrm{N}: \mathrm{Fe}$ in phytoplankton cells was smaller. For the model to produce observed phytoplankton specific growth rates with iron limitation either the Fe requirements of the phytoplankton must be lower (i.e. the cellular $\mathrm{N}: \mathrm{Fe}$ must be greater than $75471: 1$ ), Fe must be supplied at a higher rate within the pelagic ecosystem (see below), or Fe must be made available from other sources (Martin 1991).

Table 5B (left column) also gives steady state model predictions mentioned earlier for the Fe-limited chemostat containing only phytoplankton. In this case the predicted concentration of chl a exceeds observed concentrations by about 3 to 6 times and the specific growth rate of the phytoplankton is extremely low $\left(0.033 \mathrm{~d}^{-1}\right.$, the dilution rate). In contrast, under simultaneous nutrient limitation and grazing control (Table 5A, left column) chl a concentration is in the range of observations and specific growth rate is about 6 times greater than the dilution rate. These are not subtle distinctions, but characterize the fundamentally different consequences of nutrient limitation alone and 
of simultaneous nutrient limitation and grazing control. The distinctions persist despite increased availability of iron achieved by increasing either $\delta$ or $\mathrm{Fe}_{0}$ (Table 5, middle and right columns). In the Fe-limited chemostat containing only phytoplankton the specific growth rate is still too low and phytoplankton standing stock is too high. In contrast, increasing the rate of supply of $\mathrm{Fe}$ in the chemostat with phytoplankton and herbivore causes the phytoplankton specific growth to increase with little or no change in phytoplankton standing stock. While these calculations are conclusive as regards the contrast between the 2 control mechanisms (nutrient limitation alone vs simultaneous nutrient limitation and grazing control) they are, of course, crude because of various uncertainties about $\mathrm{N}$ and $\mathrm{Fe}$ (e.g. uptake kinetics, recycling characteristics, N:Fe in phytoplankton cells) in the equatorial Pacific upwelling zone.

Notice in Table 5 that under both types of control the nitrogen concentration is high and seemingly not very different. This indicates that the diagnostic processes for understanding the high nutrient/low phytoplankton stock condition are those processes controlling the concentration and specific growth rate of the phytoplankton; nitrogen concentrations can be similarly high for very different reasons.

It seems clear from these results that even if the specific growth rate of the phytoplankton is limited by availability of a trace nutrient such as iron, grazing control of phytoplankton stock is essential to reproduce the observed conditions of low phytoplankton stock and phytoplankton specific growth rates that greatly exceed the advective throughput rate in the equatorial upwelling zone. However, what is possible in a model is not necessarily so in the ocean. As noted elsewhere (Frost 1991), two other conditions must be met for grazing control to be effective.

\section{Pelagic food chain dynamics}

First, the grazing control must extend across the entire phytoplankton assemblage, with the protistan grazers able to consume efficently all types and sizes of cells. This is a likely possibility for the Pacific equatorial upwelling zone, where the phytoplankton stock is dominated by very small cells (Chavez 1989, Peña et al. 1990). Yet the situation may be more complicated, as noted in the 'Discussion'.

Second, the grazer assemblage must be insulated from potentially destabilizing predation, otherwise their stocks may be depressed, releasing phytoplankton from grazing control and allowing the phytoplankton to bloom. This is readily appreciated by considering the predictions of the simple $\mathrm{N}$-limited chemostat model with a food chain consisting of phytoplankton, a herbivore, and a primary carnivore $\left(C_{1}\right)$ population [i.e. Eqs. (1) to (5), with $C_{2}=0$ ]. Given a seemingly reasonable set of parameter values for the primary carnivore, the herbivore population is ultimately depressed and the phytoplankton stock increases until nutrients are depleted in the chemostat (Fig. 4). Thus, conditions revert to the case with phytoplankton alone in the chemostat (Fig 1).

There are 2 ways that the chemostat food chain with more than 2 trophic levels can produce conditions similar to those of the eastern Pacific equatorial upwelling. One possibility is that the primary carnivore feeds at such a low rate that it barely maintains its population against washout. However, for any $\gamma_{1}>0.066 \mathrm{~d}^{-1}$ (i.e. specific growth rate $>\delta$ ) the primary carnivore population will ultimately build up, depressing the herbivore population, and the phytoplankton will bloom, depleting nutrients as in Fig. 4.

The alternative is to add another consumer type, a secondary carnivore $\left(C_{2}\right)$ to control the primary carnivore population. Solution of the full N-limited model [Eqs. (1) to (5)] is shown in Fig. 5. Predator-prey oscillations, driven by the lagged population responses of the initially rare consumers, ultimately give way by
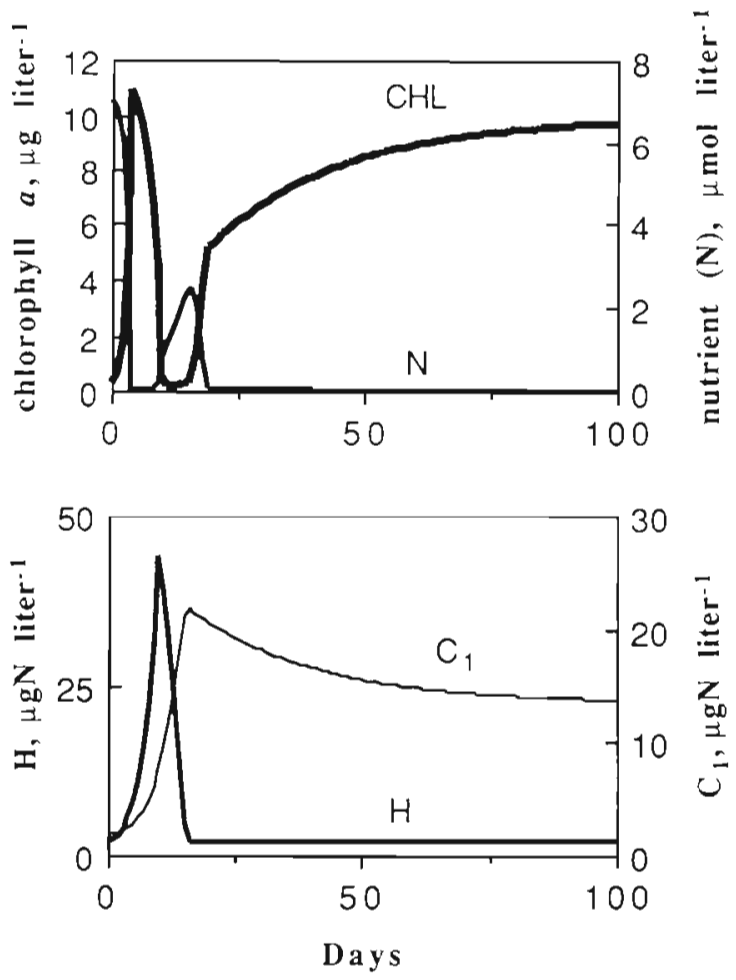

Fig. 4. Model predictions for a chemostat containing 3 trophic levels (phytoplankon, herbivore, and primary carnivorel and with nitrogen as the limiting nutrient. Initial standing stocks of consumers are $2 \mu \mathrm{gN} \mathrm{l}^{-1}$ 

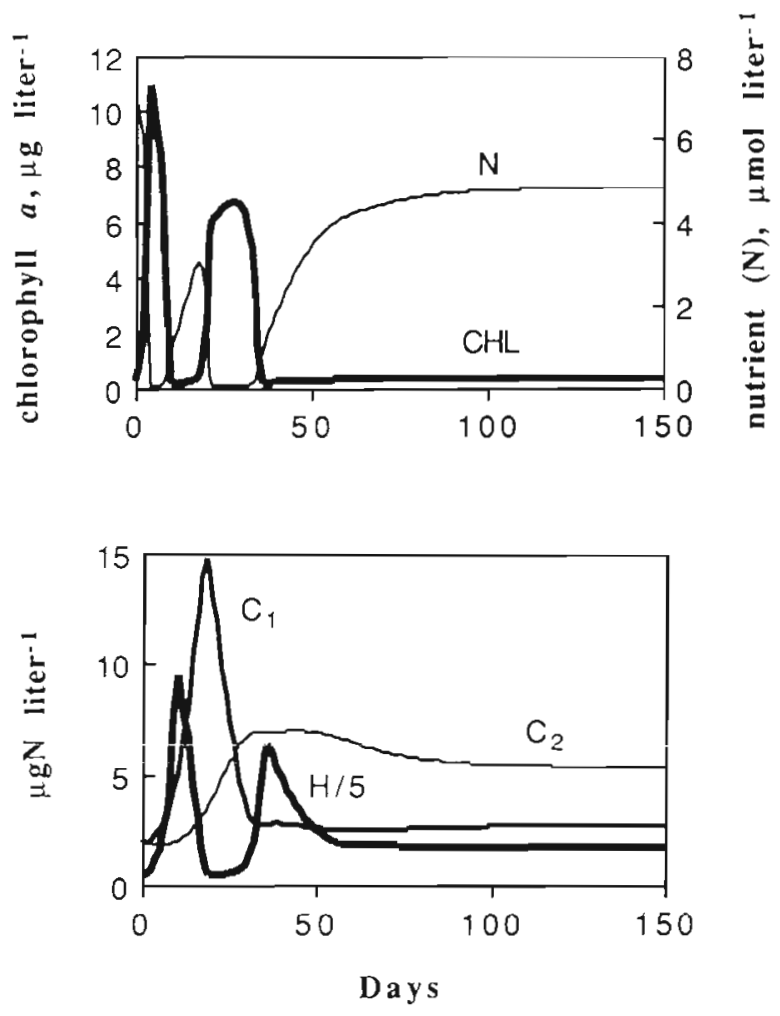

Fig. 5. Model predictions for a chemostat containing 4 trophic levels (phytoplankton, herbivore, primary and secondary carnivores) and with nitrogen as the limiting nutrient. Initial standing stocks of consumers are $2 \mu \mathrm{gN} \mathrm{l}^{-1}$. At steady state phytoplankton standing stock is $0.37 \mu \mathrm{g} \mathrm{chl} \mathrm{a} \mathrm{l}^{-1}$, nitrogen

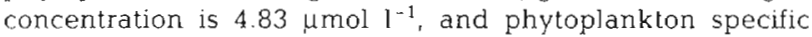
growth rate is $1.269 \mathrm{~d}^{-1}$

Day 100 to the high nutrient-low phytoplankton stock condition. That is, the secondary carnivore ultimately controls the population of primary carnivore, resulting in low predation mortality on the herbivore. The phytoplankton standing stock and nutrient concentration are again qualitatively similar to those observed in the equatorial upwelling zone of the eastern Pacific.

Although in the cases illustrated in Figs. 4 \& 5 the system eventually reaches a stable equilibrium point at steady state despite large initial perturbations, the 3 and 4-trophic level models are complex enough that with different sets of parameter values the model produces stable oscillations or even unstable or unpredictable fluctuations in stocks (chaotic behavior), as anticipated by Hastings \& Powell (1991). This would be a. subject worthy of further investigation in its own right, but is beyond the scope of this paper to present details. It is sufficient to point out that over a broad range of parameter values the 4-trophic level model produces, on average, the high nutrient/low phytoplankton stock condition seen at steady state in Fig. 5. A frequent result is that of high, but variable nutrient coupled with low, but variable phytoplankton stock. While the 4 -trophic level model is nearly as insensitive to changes in $N_{0}$ as shown for the 2-trophic level version in Table 2 , this is not true for changes in $\delta$. As $\delta$ is increased from 0.033 to $0.066 \mathrm{~d}^{-1}$ the system develops strong oscillations; $\mathrm{C}_{2}$ is threatened with wash-out from the chemostat whenever $\delta$ is a significant fraction of its growth rate. In addition, more elaborate trophic structure may or may not alter the predictions. When the primary carnivore $C_{1}$ in the simple food chain is replaced with an omnivore feeding indiscriminately on the phytoplankton and herbivore, $\mathrm{H}$ and $\mathrm{C}_{1}$ act together to maintain low phytoplankton stock. However, when the food chain is altered so that $C_{2}$ feeds indiscriminately on $C_{t}$ and $\mathrm{H}$, the outcome resembles that of the 3-trophic level model (Fig. 4); heavy predation pressure on H prevents grazing control of phytoplankton stock. Thus, several reasonable 4-trophic level food chains or webs can produce the high nutrient/low phytoplankton stock condition, provided that a large stock of grazers exists

\section{DISCUSSION}

The chemostat analogue is useful for demonstrating precisely how and under what conditions the 2 hypothesized control mechanisms, grazing and iron limitation, might account independently or together for the high nutrient/low phytoplankton stock condition observed in the equatorial Pacific upwelling zone.

In a chemostat containing only phytoplankton the specific growth rate at steady state is determined by dilution rate, while phytoplankton standing stock is determined by concentration of limiting nutrient in the inflowing medium (Eqs. 6a, c). This is the sort of equatorial upwelling zone envisaged by Martin et al. (1989). who acknowledge no role for grazing (but see Martin et al. 1991). In such an ocean, if a trace nutrient is deficient, it will cause phytoplankton stock to be lower than expected for the available concentrations of macronutrients; just how low the phytoplankton stock will be under such limitation depends directly on the ratio in which the limiting trace nutrient and macronutrients are supplied relative to ratio of the same nutrients in phytoplankton cells (Figs. 2 \& 3A). However, it was shown above that iron limitation cannot by itself account for the high nutrient/low phytoplankton stock condition without at the same time causing excessively low phytoplankton specific growth rates (Fig. 3A, Table 5B). Yet growth rates are not nearly so low in the equatorial Pacific upwelling zone (Barber \& Chavez 1991, Peña et al. 1991, Cullen et al. 1992). Nor does it appear that the observed conditions can be established and maintained by a continuous supply of 
iron from outside the pelagic ecosystem, such as input of iron from atmospheric dust (Martin 1991), for this would cause phytoplankton stock to be greater as well, and it is already too high in possible iron limitation scenarios with no external inputs (Table 5B).

In a chemostat containing phytoplankton and grazers the standing stock of the phytoplankton at steady state is determined entirely by the grazing parameters and dilution rate (Eq. 7), though at dilution rates approximating the upwelling rates in the equatorial Pacific upwelling zone this effect is minor (Table 2). Thus, for such a system containing phytoplankton and grazers it is appropriate to speak of control of phytoplankton stock by grazing. This is the sort of equatorial upwelling zone envisaged by Walsh (1976), where grazers effectively prevent the phytoplankton from accumulating and depleting nutrients. In such an ocean specific growth rate of the phytoplankton is high, being supported by high concentrations of nutrient (Table 2).

Nevertheless, specific growth rate of the phytoplankton may be less than the maximum possible in the Pacific equatorial upwelling zone (Banse in press, Barber \& Chavez 1991, Cullen et al. 1992). As shown in Tables 4 \& 5A, an additional role for limitation of phytoplankton growth rate by a trace nutrient is certainly theoretically feasible within the framework of the grazing control model. But even with severe iron limitation of phytoplankton growth, grazing control is still required both to maintain phytoplankton stock at realistically low concentrations and to maintain phytoplankton specific growth rates that are greatly in excess of advective throughput rates (Table 5A). In this event, the model indicates that increased availability of such a limiting trace nutrient from any source, including an external source such as atmospheric dust, should immediately stimulate specific growth rate of the phytoplankton, causing increased phytoplankton production rate $(A \mu)$ without a change in phytoplankton stock. However, this has not been seen in experimental enrichments to date.

In the equatorial Pacific upwelling zone, Price et al. (1991) found that iron enrichment did not affect growth rate of the phytoplankton in 24 to $48 \mathrm{~h}$ deck incubations. This agrees with results of Martin et al. (1989), who observed no effect of iron enrichment on phytoplankton production rate during $24 \mathrm{~h}$ in situ incubations in the open subarctic Pacific. As classical tests of nutrient limitation, both experiments suggest that the bulk of the indigenous phytoplankton assemblage is not iron-limited, though in the equatorial Pacific upwelling zone phytoplankton growth may be limited by some other trace nutrient if specific growth rate is indeed less than the maximum rate. However, in both experiments, as well as that of Martin et al. (1991) and
Chavez et al. (1991) in the equatorial Pacific upwelling zone, enhanced yields of phytoplankton were obtained in iron-enriched treatments after several days of incubation ('grow-out' experiments). Since changes in species composition of the phytoplankton were also observed in all experiments, it appears that iron enrichment released a normally rare component of the phytoplankton from iron limitation. In the open subarctic Pacific this phytopankton component, which appeared to be large-sized species, chicfly diatoms (Martin et al. 1989), was obviously not grazed efficiently by the indigenous grazer assemblage contained in the incubated samples. In the equatorial Pacific iron enrichment experiments (Martin et al. 1991, Price et al. 1991) small pennate diatoms increased in abundance. It was generally assumed that experimental manipulation did not alter the grazer assemblage, either by exclusion or imposed mortality of some component. However, in all iron enrichment experiments cited the control treatments did not mimic in situ conditions, making unambiguous interpretation of the experiments difficult.

An apparent natural iron enrichment was recently reported for the North Pacific subtropical gyre (DiTullio \& Laws 1991, Young et al. 1991), where concentrations of macronutrients (e.g. nitrate, phosphate) are usually very low. In this instance both phytoplankton stock and production rate appeared to increase under iron enrichment, but the time frame of the observations make this more like a 'grow-out' experiment. That is, even if specific growth rate did not change, production rate would be higher late in the enrichment episode because of increased phytoplankton stock. Although DiTullio \& Laws (1991) present evidence, based on 'chemotaxonomic identification', suggesting that all major taxonomic classes of phytoplankton increased in abundance, the changes in species composition would have to be known to exclude the possibility that rare inefficiently grazed species of several classes were not primarily responsible for the increase. This case is further complicated by the simultaneous increase in nitrate during the enrichment event.

More immediately relevant to the Pacific equatorial upwelling zone are occurrences of phytoplankton blooms and high phytoplankton production rates in waters over the Galapagos Islands platform (Jimenez 1981, Feldman 1986). Barber \& Chavez (1991) suggest that the phytoplankton blooms occur because of increased availability of iron derived from underlying sediments on the Galapagos platform. Here also a key observation is species composition of the phytoplankton in the blooms around the Galapagos. Jimenez (1981) found that diatoms 'of the same genera or species that dominate in other upwelling regions' 
were most abundant in terms of cell concentrations in the blooms. Presumably these were large-sized species of diatoms, but no data were given. Large diatoms may be particularly susceptible to iron limitation (Hudson \& Morel 1990), and their abundance is unlikely to be controlled by grazing alone (Frost 1991).

A reconciliation of the model predictions and results of experimental and natural iron enrichments seems clcar. The circumstance in which the growth rate of a rare, inefficiently grazed component of the phytoplankton is severely limited by availability of a trace nutrient is comparable to the case of the chemostat containing only phytoplankton. As shown in Fig. $3 \mathrm{~A}$ and Table 5B, nutrient limitation would indeed have to be severe to account by itself for the persistent scarcity of such species in nature, though sinking losses could also be important to large-sized species (Chavez et al. 1991). Nevertheless, increased availability of the limiting nutrieni, ds in an iron entichuent expeninteni, would not immediately be detectable in growth rate of the phytoplankton assemblage as a whole if the nutrient-limited component was initially very rare. Yet if rolcasc from nutricnt limitation resulted in grcatly enhanced growth rates, say in the neighborhood of 0.6 to $0.8 \mathrm{~d}^{-1}$, then with no grazing the rare phytoplankton component could increase in abundance by 20 to 55 times in only $5 \mathrm{~d}$. Hence, the formerly very rare component could become conspicuous in a 'grow-out' experiment.

This interpretation of the results of experimental and natural iron enrichments seems most consistent with the facts, and together with the model results herein suggests dual regulation of the level of biological production in the Pacific equatorial upwelling zone. That is, concentrations of macronutrients remain high and phytoplankton stocks remain low in the surface layer both because grazing control keeps the dominant. relatively rapidly-growing phytoplankton in check and because rare, inefficiently grazed components of the phytoplankton are limited in their growth by availability of iron (and possibly other trace nutrients). It seems likely, then, that artificially increased availability of iron (Martin in press) would indeed lead to increased abundance of the rare, inefficiently grazed, severely iron-limited species of phytoplankton and to draw-down of macronutrients in the surface layer. However, the impact of such manipulation on the natural pelagic food web is completely unpredictable.

Acknowledgements. We thank Karl Banse and Edward Laws for constructive critical comments on an earlier version of this paper. Andrew Clarke arranged for facilities in the Marine Life Sciences Division، British. Antarctic Survey, where some this work was carried out. Francisco Chavez kindly provided unpublished data on àmonium concentrations. Research supported by NSF grants OCE8917671 and OCE9101909 to B.W.F, and an ONR graduate fellowship to N.C.F. Contribution 1937 from the School of Oceanography, University of Washington.

\section{LITERATURE CITED}

Banse, K. (1992). Grazing, the temporal changes of phytoplankton concentration, and the microbial loop in the open sea. In: Falkowski, P. G., Woodhead, A. D. (eds.) Primary productivity and biogeochemical cycles in the sea. Plenum Press, New York, p. 409-440

Barber, R. T. Chavez, F. P. (1991). Regulation of primary productivity rate in the equatorial Pacific Ocean. Limnol Oceanogr. 36: 1803-1815

Bender, M. L., McPhaden, M. J. (1990). Anomalous nutrient distribution in the equatorial Pacific in April 1988: evidence for rapid biological uptake. Deep Sea Res. 37 . $1075-1084$

Caperon, J. (1975). A trophic level ecosystem model analysis of the plankton community in a shallow-water subtropical estuarine embayment. Estuar. Res. 1.691-709

Chavez, F. P. (1989). Size distribution of phytopiankton in the central and eastern tropical Pacific. Global biogeochem. Cycles 3: 27-35

Chavez, F. P., Buck, K. R., Barber, R. T (1990). Phytoplankton taxa in relation to primary production in the equatorial Pacific. Deep Sed Res. 37: 1733-1752

Chavez, F. P., Buck, K. R., Coale, K. H., Martin, J. H., DiTullio, G. R., Welschmeyer, N. A., Jacobson, A. C., Barber, R. T. (1991). Growth rates, grazing, sinking, and iron limitation of equatorial Pacific phytoplankton. Limnol. Oceanogr. 36: 1816-1833

Chisholm, S., Morel, F. (eds.) (1991). What controls phytoplankton production in nutrient-rich areas of the open sea? Limnol, Oceanogr. 36: Preface

Cullen, J. J., Lewis, M. R., Davis, C. O., Barber, R. T (1992) Photosynthetic characteristics and estimated growth rates indicate that grazing is the proximate control of primary production in the equatorial Pacitic. J. geophys. Res. 97 (C.1): 639-654

DiTullio, G. R., Laws, E. A. (1991). Impact of an atmosphericoceanic disturbance on phytoplankton community $\mathrm{dy}$ namics in the North Pacific central gyre. Deep Sea Res. 38 $1305-1329$

Dortch, Q. (1990). The interaction between ammonium and nitrate uptake in phytoplankton. Mar. Ecol. Prog. Ser. 61 $183-201$

Dugdale, R. C., Wilkerson, F P., Barber, R. T., Chavez, F. P. (1992). Estimating new production in the equatorial Pacific Ocean at $150^{\circ}$ W. J. geophys. Res. 97 (C1): 681-686

Eppley, R. W. (1989). New production: history, methods problems. In: Berger, W. H. Smetacek, V. S., Wefer, G. (eds.) Productivity of the ocean: present and past. J. Wiley. Chichester, p. 85-97

Fasham, M. J. R., Ducklow, H. W., Mckelvie, S. M. (1990). A nitrogen-based model of plankton dynamics in the oceanic mixed layer. J. mar. Res. 48: 591-539

Feldman, G. C. (1986). Patterns of phytoplankton production around the Galapagos Islands. In: Bowman, M. J., Yentsch, C. M., Peterson, W. T. (eds.) Tidal mixing and plankton dynamics, lecture notes on coastal and estuarine studies, Vol. 1.7. Springer-Verlag, Berlin p. 77-106

Fenchel, T. (1987). Ecology of protozod. Science Tech Publishers, Madison, Wisconsin

Frost, B. W. (1991). The role of grazing in the nutrient-rich areas of the open sea. Limnol. Oceanogr. 36: 1616-1630 
Hastings, A., Powell, T. (1991). Chaos in a three-species tood chain. Ecology 72: 896-903

Heinbokel, J. F. (1978). Studies on the functional role of tintinnids in the Southern Califormia Bight. I. Girazing and growth rates in laboratory cultures. Mar. Biol. 47 : $177-189$

Herbert, D., Elsworth, R. Telling, R. C. (1956). The continuous culture of bacteria: a theoretical arid experimental study. J. gen. Microbiol. 14:601-622

Hudson, R. J. M., Morel, F. M. M. (1990). Iron transport in marine phytoplankton: kinetics of cellular and medium coordination reactions. Limnol. Oceanogr. 35: 1002-1020

Jimenez, R. (1981). Composition and distribution of phytoplankton in the upwelling system of the Galapagos Islands. In: Richards, F. A. (ed.) Coastal upwelling, coastal and estuarine science. Am. Geophys. Un., Washington, D.C., p. $327-338$

King, F. D. (1987). Nitrogen recycling efficiency in steadystate oceanic environments. Deep Sea Res. 34: 843-856

Martin, J. H. (1991). Iron still comes from above. Nature, Lond. 353: 123

Martin, J. H. (1992). Iron as a limiting factor in oceanic productivity. In: Falkowski, P. G., Woodhead, A. D. (eds.) Primary productivity and biogeochemical cycles in the sea. Plenum Press, New York, p. 123-127

Martin, J H., Gordon, R. M. (1988). Northeast Pacific iron distributions in relation to phytoplankton productivity. Deep Sea Res. 35: 177-196

Martin, J. H., Gordon, R. M., Fitzwater, S., Broenkow, W. W. (1989). VERTEX: phytoplankton/iron studies in the Gulf of Alaska. Deep Sea Res. 36: 649-680

Martin, J. H., Gordon, R. M., Fitzwater, S. E. (1991). The case for iron. Limnol. Oceanogr. 36: 1793-1802

Peña, M. A., Lewis, M. R., Harrison, W. G. (1990). Primary

This article was submitted to the editor productivity and size structure of phytoplankton biomass on a transect of the equator at $135^{\circ} \mathrm{W}$ in the Pacific Ocean Deep Sea Res. 37: 295-315

Peña, M. A., Lewis, M. R, Harrison, W. G. (1991). Particulate organic matter and chlorophyll in the surface layer of the equatorial Pacific ocean along $135^{\circ}$ W. Mar. Ecol. Prog Ser $72: 179-188$

Philander, S. G. (1990). El Niño, La Nina, and the Southern Oscillation. Academic Press, San Diego

Price, N. C., Stevens, L. (1982). Fundamentals of enzymology. Oxford Univ. Press, Oxford

Price, N. M., Andersen, L. F., Morel, F. M. M. (1991). Iron and nitrogen nutrition of equatorial Pacific plankton. Deep Sea Res. 38: 1361-1378

Redfield, A. C., Ketchum, B. H., Richards, F. A. (1963). The influence of organisms on the composition of seawater. In: Hill, M. N. (ed.) The sea, Vol. 2. Interscience Publishers, New York, p. 26-77

Thingstad, T F., Sakshaug, E. (1990). Control of phytoplankton growth in nutrient recycling ecosystems. Theory and terminology. Mar. Ecol. Prog. Ser, 63: 261-272

Sunda, W. G., Swift, D. G., Huntsman, S. A. (1991). Low iron requirement for growth in oceanic phytoplankton. Nature, Lond. 351: 55-57

Walsh, J. J. (1976). Herbivory as a factor in patterns of nutrient utilization in the sea. Limnol. Oceanogr. 21:1-13

Wright, R. T (1988). A model for short-tern control of the bacterioplankton by substrate and grazing. Hydrobiologia 159: $111-117$

Young, R. W., Carder, K. L., Betzer, P. R., Costello, D. K., Duce R. A., DiTullio, G. R., Tindale, N. W., Laws, E. A., Uematsu, 1., Merrill, J T., Feely, R. A. (1991). Atmospheric iron inputs and primary productivity: phytoplankton responses in the North Pacific. Global biogeochem. Cucles 5: 119-134

Manuscript first received: January 20, 1992

Rivised version accepted: April 29, 1992 